\title{
Added value of post-mortem computed tomography (PMCT) to clinical findings for cause of death determination in adult "natural deaths"
}

\author{
M. E. M. Vester ${ }^{1,2,3,4}$ - R. R. van Rijn ${ }^{2,3,4}$ - W. L. J. M. Duijst ${ }^{5,6} \cdot$ L. F. M. Beenen ${ }^{2} \cdot$ M. Clerkx ${ }^{7}$ R. J. Oostra ${ }^{4,7}$
}

Received: 3 June 2019 / Accepted: 27 November 2019/Published online: 18 December 2019

(C) The Author(s) 2019

\begin{abstract}
Purpose The aim of this study was to investigate whether post-mortem computed tomography (PMCT) provides additional information regarding the cause of death and underlying diseases in a general practitioners' (GP), out-of-hospital population. Methods and materials Bodies donated to our anatomy department between January 2014 and January 2018, who consecutively underwent a total body PMCT and had given permission for retrieval of their medical records during life, were included. PMCT scans were assessed by a radiologist and compared with the cause of death as stated in the medical records. Discrepancies were analyzed with an adjusted Goldman classification.

Results Ninety-three out of the 274 scanned donors during the inclusion period had given consent for the retrieval of their medical records, of which 79 GP's responded to the request thereof (31 men, 48 women, average age 72.8 years, range 36-99). PMCT identified $49(62 \%)$ cases of cancer, $10(12.7 \%)$ cardiovascular diseases, $8(10.1 \%)$ severe organ failures, $5(6.3 \%)$ cases with signs of pneumonia, 2 (2.5\%) other causes, and 7 (8.9\%) cases without an (underlying) definitive cause of death. Eleven major discrepancies on the Goldman classification scale, with possible relevance to survival between PMCT and GP records, were identified.

Conclusion PMCT can have added value for the detection of additional findings regarding the cause of death in an out-ofhospital, GP's population, especially to identify or exclude major (previously non-diagnosed) underlying diseases.
\end{abstract}

Keywords Autopsy $\cdot$ Tomography $\cdot$ X-ray computed $\cdot$ Pathology $\cdot$ Anatomy

M. E. M. Vester

marloes.vester@gmail.com

1 Academic Medical Center Amsterdam, University of Amsterdam, Amsterdam, Netherlands

2 Department of Radiology and Nuclear Medicine, Amsterdam UMC, University of Amsterdam, Room G2-231, Meibergdreef 9,

Amsterdam, the Netherlands

3 Department of Forensic Medical Investigations, Netherlands Forensic Institute, The Hague, the Netherlands

4 Amsterdam Center for Forensic Science and Medicine, Amsterdam, the Netherlands

5 Faculty of Law, Maastricht University, Maastricht, the Netherlands

6 Department of Forensic Medicine, GGD IJsselland, Zwolle, the Netherlands

7 Department of Medical Biology, Section Clinical Anatomy and Embryology, Amsterdam UMC, University of Amsterdam, Amsterdam, the Netherlands

\author{
Abbreviations \\ GP General practitioner \\ PMCT Post-mortem computed tomography
}

\section{Introduction}

Cause and manner (natural or non-natural) of death assessment, as assessed by the attending physician or municipal coroner, is a frequent topic of public and scientific debate [1-4]. In the Netherlands, registration and documentation on the death certificate are both legally obligatory and important for population statistics and health care quality control [5]. In natural deaths, cause of death determination is often based on medical history and circumstantial evidence rather than a postmortem in-depth medical examination. This sometimes allures to conclusions such as dying of "old age" when the cause of death remains unknown. Furthermore, even with appropriate diagnostic tests shortly before the demise available 
(hospitalized patients), up to a third of cause of death diagnosed in the Netherlands are incorrect [3]. For an accurate cause of death determination, autopsy is considered the reference standard.

Clinical autopsy however is a labor-intensive, time-consuming, and often costly procedure, which in the Netherlands is not paid for by health care insurance companies. Out-of-hospital autopsies are usually more cumbersome to arrange as general practitioners (GP) have no direct access to hospital pathology services. Furthermore, already present ante-mortem imaging and laboratory results leading to a possible cause of death, or on the other hand, moral objections can hinder professionals to ask relatives for autopsy permission [6]. The invasive character of autopsy can be deterring to relatives or be in conflict with by their religion. As a result of a combination of all the aspects mentioned, the number of autopsies has been decreasing worldwide over the last decades [7-9].

In recent years, the use of post-mortem computed tomography (PMCT) as a non-invasive, relatively cheap, fast, and widely available technique has been proposed to assist in cause of death determination. This could improve health care quality control, mortality statistics, prevention programs, and possibly the detection of (unknown) hereditary diseases. In a trauma setting, PMCT has proven to be a good alternative for those cases in which autopsy is not possible [10]. Yet, PMCT as a diagnostic tool for cause of death determination has not been evaluated in out-of-hospital deaths of a GP population. If PMCT can also improve cause of death diagnosis and identification of underlying diseases in GP patients, this might be a more acceptable, noninvasive, and affordable alternative to autopsy in this population as well as a valuable tool for professional quality control. Therefore, the purpose of this study was to answer two questions. Does PMCT provide additional information regarding the cause of death and underlying diseases in a GP population? Secondly, does this PMCT-based diagnosis comply or oppose with cause of death as determined by the GP?

\section{Materials and methods}

\section{Legal foundation, study design, and study population}

On the basis of Article 67-69 of the Burial Act, adult inhabitants of the Netherlands can register in any of the eight Dutch medical universities, to donate their body to science and education. Since 2014, all donors of the Amsterdam UMC, University of Amsterdam, body donation program, sign an additional statement in which the donors give permission to retrieve their medical records. In addition, all living donors, registered between 1-1-2008 and 31-12-2013 ( $n=1465)$, were contacted by mail in order to obtain the same permission. This request had a response rate of 1201 (82\%), including four $(0.003 \%)$ objections to retrieval of medical records. For this study, a waiver was issued by the medical ethical committee of our hospital.

In this case series, bodies donated to the anatomy department of the Amsterdam UMC, University of Amsterdam, arriving between January 2014 and January 2018 and who underwent a total body PMCT, were included. All donors died either due to natural causes, as reported by the GP, or in case of a non-natural cause of death, e.g., euthanasia, were released from legal custody by the public prosecutor. Cases without permission to obtain medical history were excluded from this study. GP's were contacted to obtain the medical records by the first author (MV). Specifically, information regarding the cause of death was requested along with a summary of the medical history, medication, and known hereditary diseases. No gender, age, post-mortem interval, body mass index, or amputations/body deformity limitations were applied in this study.

\section{Post-mortem imaging}

As part of the standard workup procedure for educational purposes, a total body PMCT was made as soon as possible upon arrival at the department of anatomy, before embalming. Due to personnel or technical difficulties, PMCT scanning was not always possible. During the CT scanning procedure, the arms were crossed over the thoracoabdominal region, in a supine position within a body bag (Fig. 1). Up to June 2015, a Siemens Sensation 64® CT scanner (Siemens Healthineers, Erlangen, Germany) was used with set parameters for $3 \mathrm{~mm}$ slice thickness; $3 \mathrm{~mm}$ increments; $120 \mathrm{kV}$ tube voltage; $325 \mathrm{mAs}$ tube current; B30f (soft tissue filter) convolution kernel. After June 2015, a Siemens SOMATOM Force® dual source CT scanner (Siemens Healthineers, Erlangen, Germany) with dual energy capabilities became available. The dual energy scans were made at $100 \mathrm{kV}$ with $750 \mathrm{mAs}$ and $\mathrm{Sn} 150 \mathrm{kV}$ with $375 \mathrm{mAs}$. Collimation was $2 \times 192 \times$ $0.6 \mathrm{~mm}$, with axial and coronal reconstructions ( $1 \mathrm{~mm} \mathrm{Br40}$ and Qr40 soft tissue filters and $3 \mathrm{~mm} \mathrm{Br59}$ bone filters), along with dedicated reconstructions for dual energy post-processing. No clinical autopsy or other invasive post-mortem procedures were performed prior to embalming.

\section{Data analysis}

A forensic radiologist with 14 years of experience, in PMCT, (RvR) assessed the scans for the cause of death, underlying diseases, and other abnormalities. These assessments were initially made without the medical records and were reviewed a second time in a different order at least half a year later with knowledge of the medical records. All findings were recorded on a standardized case report form. Findings were recorded per body location and classified into (1) tumors and/or metastases, (2) cardiovascular diseases (e.g., myocardial infarction), (3) signs of infections, (4) signs of organ failure (liver 
Fig. 1 Scanning of study body in a body bag on the Siemens SOMATOM Force ${ }^{\circledR}$ Dual source CT scanner

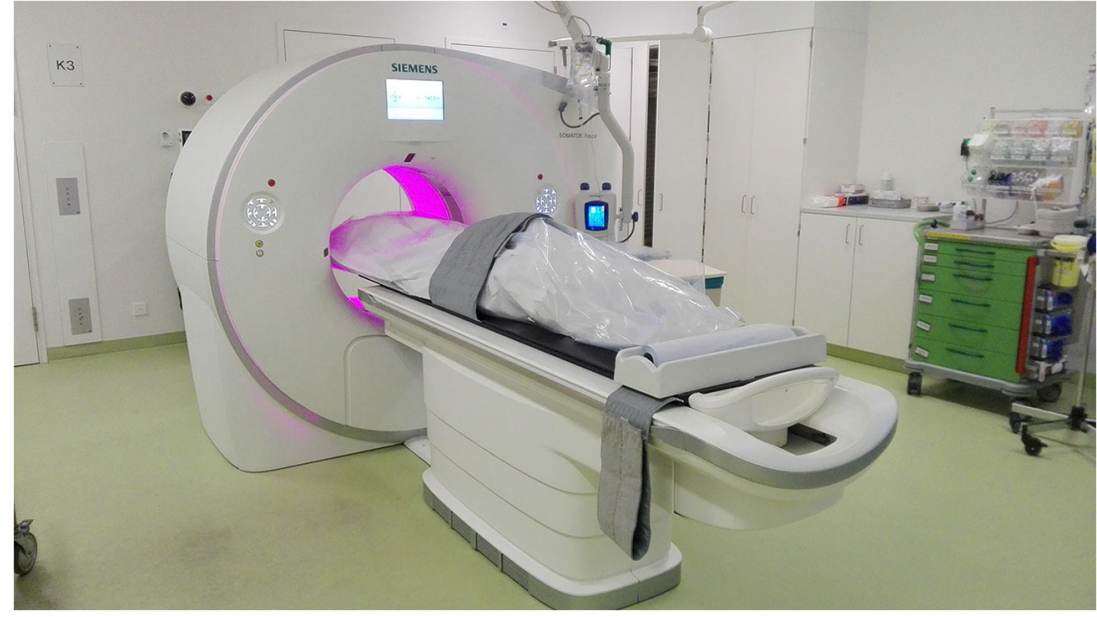

cirrhosis, severe COPD, renal failure), (5) other; not relevant to the cause of death (gallstones, old fractures, rheumatism), and (6) signs of surgery or interventions (stent, coils, prostheses, pacemakers).

Cause of death as diagnosed by PMCT was compared with what was stated in the medical records. Analysis of any discrepancies between the two were scored according to the classification of Goldman et al. [1], later adapted by Battle et al. and Schwanda-Burger et al. $[11,12]$. This discrepancy classification method was originally developed for ante-mortem clinical diagnosis and post-mortem autopsy comparisons (Table 1). For this study, discrepancies were scored independently by three individuals: two radiologists (RR and LB) and one forensic physician (WD). In case of differences, a consensus was met after discussion.

\section{Results}

\section{Subject identification}

During the four-year study period, 730 bodies were donated to our anatomy department (Fig. 2). Ninety-three out of the 274

Table 1 Classification of discrepancies between clinical records and PMCT results $[1,12]$

\begin{tabular}{ll}
\hline Classification & Explanation \\
\hline Class I & $\begin{array}{l}\text { Major discrepancies, with prolonged survival or healing } \\
\text { Class II }\end{array}$ \\
$\begin{array}{l}\text { Major discrepancies, without prolonged survival or } \\
\text { healing } \\
\text { Class III }\end{array}$ & $\begin{array}{l}\text { Minor discrepancies } \\
\text { diagnosis that would have }\end{array}$ \\
Class IV & $\begin{array}{l}\text { Minor discrepancies, diagnosis that would have had } \\
\text { epidemiological or genetic consequences }\end{array}$ \\
Class V & $\begin{array}{l}\text { Non-discrepant results } \\
\text { Class VI }\end{array}$ \\
\hline
\end{tabular}

scanned donors had given consent for the retrieval of their medical records, of which 79 GP's responded to the request. In total 31 men and 48 women were included with an average age of 72.8 years (range 36-99 years, SD 10.1). Median time between death and arrival at the anatomy department and PMCT was $27 \mathrm{~h}$ (range 4-72 h, SD 17.2).

\section{Medical records}

According to the medical records provided by the GP's, 50 cases $(63.3 \%)$ received no specific last phase of life treatment, 13 cases (17.3\%) died in the course of palliative care and 16 died a nonnatural death including 15 cases of euthanasia (20\%), and a single case of suicide (1.3\%). Recorded causes of death, including grounds for palliative care or euthanasia, were mostly cancer $(n=48,60.8 \%)$. Other causes were cardiovascular diseases $(n=$ $11,13.9 \%)$, organ failure $(n=7,8.9 \%)$, infections $(n=3,3.8 \%)$, or other/unknown $(n=4,5.1 \%)$ (Fig. 3$)$.

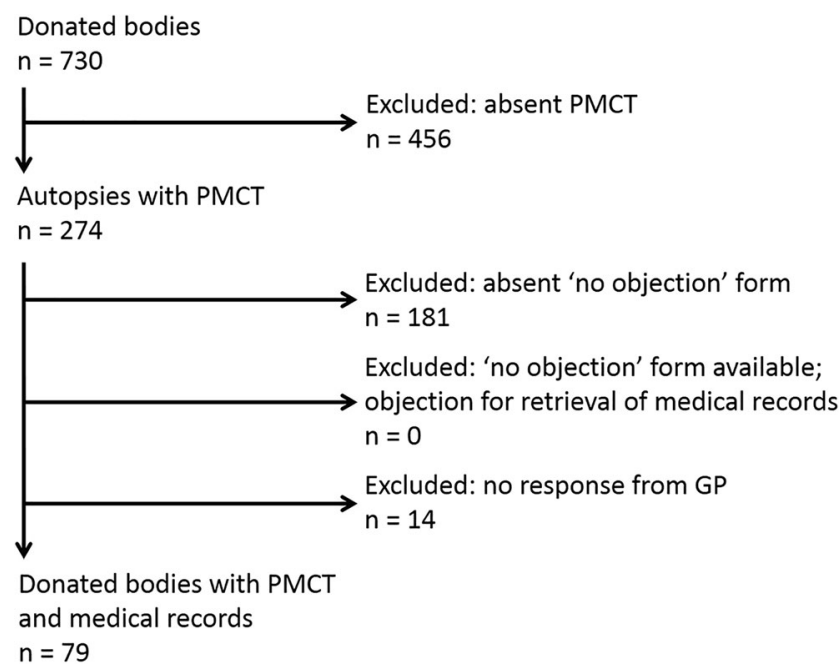

Fig. 2 Flow diagram of selected cases donated from 1 to 1-2014 to 1-12018 
Fig. 3 Cause of death as determined by the GP clinically and by the radiologist based on PMCT

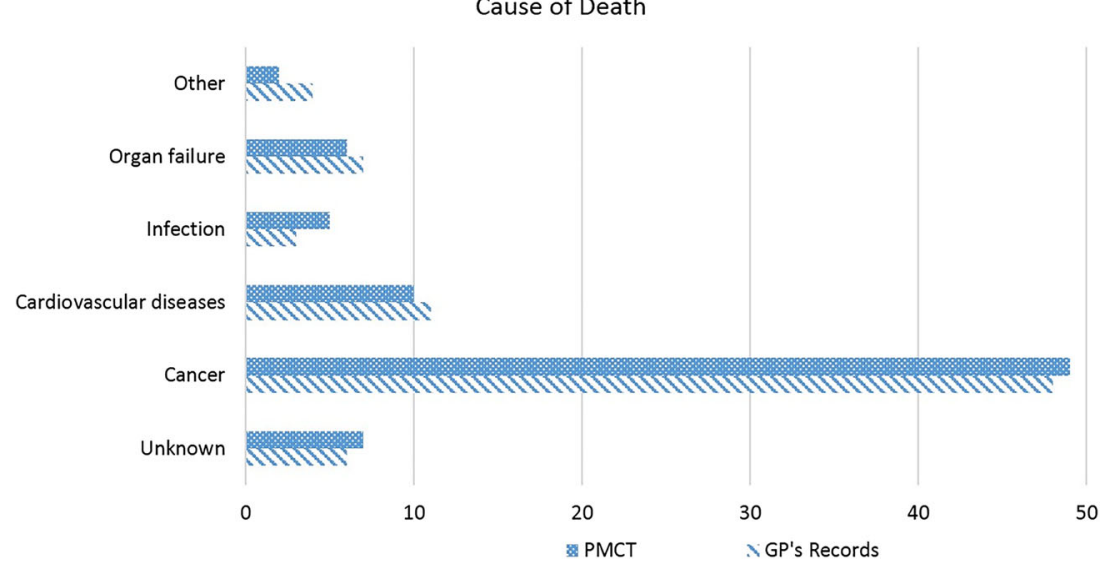

\section{Post-mortem computed tomography}

Signs of palliative care of euthanasia are non-existent on PMCT and were thus not found in any of the concerning cases, nor were there signs of suicide. In 49 (62\%) cases, cancer was diagnosed, in $10(12.7 \%)$ cases severe cardiovascular diseases, in $8(10.1 \%)$ cases signs of terminal organ failure (e.g. COPD), in 5 (6.3\%) cases signs of infection (pneumonia), 2 (2.5\%) other causes, and in 7 (8.9\%) cases no (underlying) radiological diagnosis of the cause of death could be established (Fig. 3). Assessments on cause of death on PMCT did not alter after medical information was given to the radiologist.

\section{PMCT comparison with medical records}

Added value of PMCT to GP records was found in $12(15.2 \%)$ cases, consisting of 11 major discrepancies with relevance to survival (class I discrepancies) (Table 2) and 1 major discrepancy without influence to survival (class II discrepancy) (Fig. 5). Two of these class I discrepancies were subjects who died after palliative care. PMCT was also of additional value for a single case of undiagnosed and untreated osteomyelitis (minor discrepancy; classification score III). Sixteen cases $(20.3 \%)$ were scored as non-classifiable (classification VI) because PMCT was unable to identify the cause of death or underlying disease, including the single suicide case. For

Table 2 Cases with major discrepancies with relevance to survival (Goldman classification I) between PMCT and GP records (standard care comprehends continuation of treatment without specific last phase of life treatment such as palliative care)

\begin{tabular}{|c|c|c|c|c|c|c|}
\hline No & Sex & Age & GP's diagnosis & PMCT diagnosis & $\begin{array}{l}\text { Last/final } \\
\text { care }\end{array}$ & $\begin{array}{l}\text { Discr. } \\
\text { score }\end{array}$ \\
\hline 1 & $\mathrm{~F}$ & 69 & Metastasised lung carcinoma & Metastasised lung carcinoma with signs of a pneumonia & $\begin{array}{l}\text { Standard } \\
\text { care }\end{array}$ & I \\
\hline 2 & M & 71 & Unknown cause of death & $\begin{array}{l}\text { Lytic bone lesions DD multiple myeloma, metastasised } \\
\text { carcinoma (Fig. 4) }\end{array}$ & $\begin{array}{l}\text { Standard } \\
\text { care }\end{array}$ & I \\
\hline 3 & M & 79 & Aspergilloma & $\begin{array}{l}\text { Lesion left upper lobe and pneumonia left lower lobe with } \\
\text { pleural empyema }\end{array}$ & $\begin{array}{l}\text { Palliative } \\
\text { care }\end{array}$ & I \\
\hline 4 & $\mathrm{~F}$ & 69 & $\begin{array}{l}\text { Respiratory insufficiency due to st. IV } \\
\text { adenocarcinoma NSCLC }\end{array}$ & Pneumonia & $\begin{array}{l}\text { Standard } \\
\text { care }\end{array}$ & I \\
\hline 5 & $\mathrm{~F}$ & 88 & Pneumonia and clostridium difficile infection & Congestive heart failure & $\begin{array}{l}\text { Standard } \\
\text { care }\end{array}$ & I \\
\hline 6 & $\mathrm{~F}$ & 77 & Probably lung carcinoma & No abnormalities at PMCT (no lung abnormalities) & $\begin{array}{l}\text { Standard } \\
\text { care }\end{array}$ & I \\
\hline 7 & M & 74 & Metastasised stomach carcinoma & Metastasised carcinoma, probably pancreatic carcinoma & $\begin{array}{l}\text { Standard } \\
\text { care }\end{array}$ & I \\
\hline 8 & $\mathrm{~F}$ & 66 & Metastasised stomach carcinoma & $\begin{array}{l}\text { Metastasised stomach carcinoma with untreated } \\
\text { carcinomatous pleurisy }\end{array}$ & $\begin{array}{l}\text { Standard } \\
\text { care }\end{array}$ & I \\
\hline 9 & $\mathrm{~F}$ & 71 & Hospitalisation due to gallbladder perforation & $\begin{array}{l}\text { Severe emphysema, mediastinal lymphadenopathy; } \\
\text { infection }\end{array}$ & $\begin{array}{l}\text { Standard } \\
\text { care }\end{array}$ & I \\
\hline 10 & M & 90 & Hospitalisation due to gallbladder perforation & Metastasised carcinoma & $\begin{array}{l}\text { Palliative } \\
\text { care }\end{array}$ & I \\
\hline 11 & $\mathrm{~F}$ & 85 & Myocardial infarction-atrial fibrillation & Metastasised carcinoma & $\begin{array}{l}\text { Standard } \\
\text { care }\end{array}$ & I \\
\hline
\end{tabular}




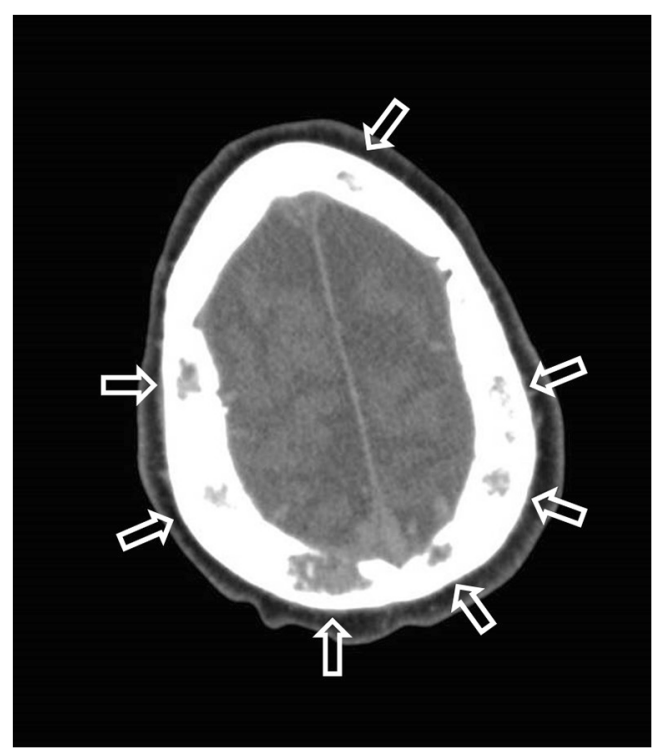

Fig. 4 Lytic bone lesions in the cranial bones due to either metastasised carcinoma or multiple myeloma, unknown to the General Practitioner

the remaining 50 cases $(63.3 \%)$, there was no discrepancy between clinical diagnosis and PMCT findings (classification score V). Discussion between the different observers was needed in 10 out of the 79 cases to reach consensus on the allocated discrepancy scores.

\section{Discrepancy scores}

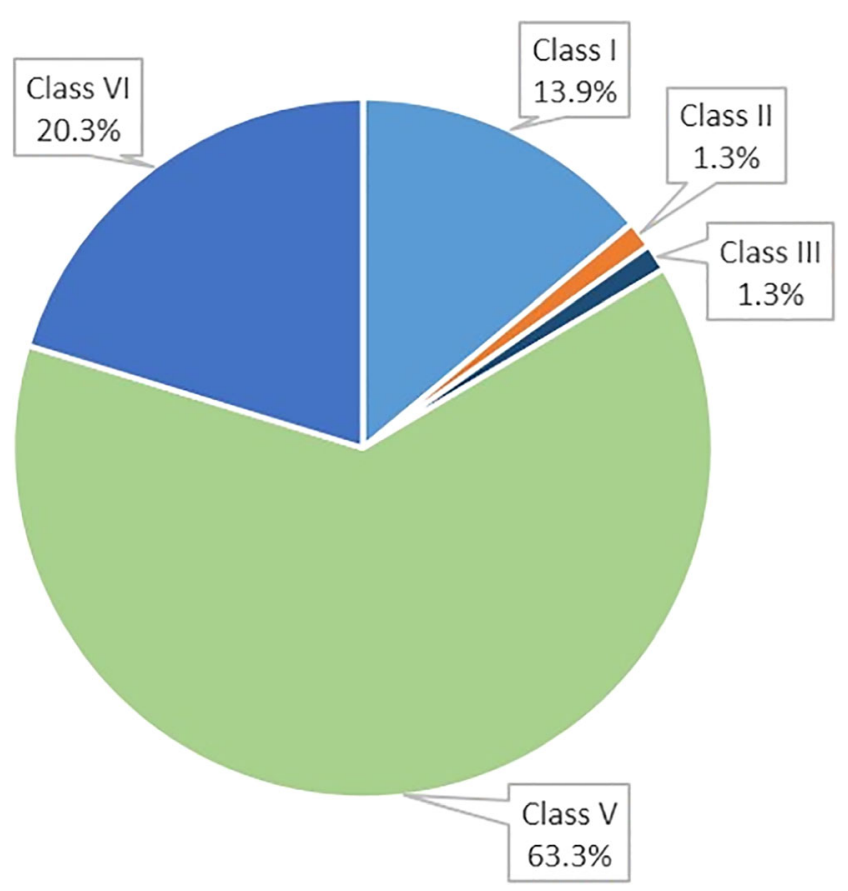

Fig. 5 Abnormalities (potentially) relevant to the cause of death

\section{Discussion}

Our results indicate that in the majority of cases PMCT does not provide additional information regarding the cause of death. However, in 11 out of 79 cases (13.9\%), a major discrepancy was noted in diagnosis between GP documents and PMCT results, which would have required treatment and could have possibly prolonged survival. These finding imply that PMCT, though as a single modality is known to be an unreliable reference standard for cause of death determination $[13,14]$, does seem to be a reliable method for identification of additional information regarding the cause of death and underlying diseases in a GP's practice population. Especially, since autopsy is generally uncommon in this group. Autopsy, as noted in the introduction, is the reference standard for cause of death determination and self-control of medicine [15]. When performed in an experienced setting and without histological examination, autopsy is a relatively quick procedure which should be always pursued if there is a question related to the cause of death. However, autopsy in general has become less common over the last decades due to, among others, its invasive character. There has been a decrease of $0.7 \%$ per year for in-hospital deaths in the Netherlands between 1977 and 2011 [16]. It has been postulated that this decrease in post-mortem examinations might cause for important complications and disorders to be missed. Consequently, this causes a decrease in accurate statistics and health care quality control $[3,16,17]$.

The priority of death investigations in the Netherlands lies with differentiation between natural and non-natural deaths, with the actual cause of death secondary to that. But, postmortem cause of death evaluation and diagnosis are, among others, essential to medical quality control and identification of previously unknown genetic diseases [18]. Moreover, epidemiological statistics form the basis of education, funding, and research are related to the cause of death determination. According to the Statistics Netherlands for instance, acute cardiovascular incidents of both ischemic and rhythmic origin are frequently assigned as the cause of death, adding up to $21.1 \%$ [19]. This results amongst others in a higher availability of research funding for cardiovascular diseases. Currently, GP's are in most cases limited to exploration of the medical history and a physical external examination for their cause of death conclusions. Distinguishing between death due to an acute myocardial infarction, (ischemic) stroke, thromboembolism, rupture of an (unknown) aneurysm or other causes by solely the medical history and a physical external examination is possible, but can be difficult. In some cases, this is too little evidence for an accurate determination of the cause of death. Subsequently, the determination of the cause of death is based on probability, which is, among others, based on the national epidemiological statistics. Thenceforward, the cause of death 
documents are used to determine these statistics, hence confirming itself, causing a circle reasoning.

The next step in post-mortem imaging is contrastenhanced PMCT (PMCT angiography; PMCTA) or PMCT combined with, e.g., toxicology or targeted biopsies (minimal invasive autopsy, MIA). In a prospective study of 210 cases, a cause of death was determined by PMCTA in $92 \%$ and was superior for trauma and hemorrhages [14], though pulmonary thromboembolism was better detected by autopsy. Overall, PMCTA had 6\% major discrepancies compared with PMCTA combined with autopsy, and autopsy had 5\% major discrepancies. Furthermore, the combination of PMCTA and autopsy showed superior results for the detection of abnormalities and the cause of death in 500 cases [13]. Here, autopsy, PMCT, and PMCTA individually detected $61.3 \%, 76.0 \%$, and $89.9 \%$ findings, respectively. PMCT and PMCTA proved to be superior over autopsy especially for skeletal and vascular lesions. A large systematic review, in suspected natural deaths, showed that PMCT combined with MRI gives the best results of non-invasive techniques for the cause of death determination with $70 \%$ agreement with autopsy. Minimal invasive autopsy (PMCT, PMCTA, and biopsy) achieved a 90.9\% agreement [20]. Nonetheless, a recent study argues that biopsies are only an alternative when consent for an autopsy cannot be obtained, since they found that CT-guided post-mortem biopsies of the lungs had a mediocre predictive value [21].

Our study has some limitations. Though the study population is representative in age distribution for the general population, it is a relatively small sample size. Secondly, death certificates would ideally be compared with clinical autopsies, macroscopic, and/or microscopic internal examination. Yet, death certificates are anonymous in the Netherlands and thus unavailable for a retrospective study, leaving the sometimes incomplete GP's records for review. PMCT as a diagnostic tool has some important limitations as well. Even though PMCT can identify signs of a possible pneumonia, the definite diagnosis cannot be made without clinical symptoms and/or laboratory tests. Furthermore, dementia is one of the most important causes of death, yet it is a clinical diagnosis based on symptoms [22, 23], and it is thus impossible to designate this as the cause of death by PMCT. Euthanasia does not leave traces detectable by PMCT, though this does not pose a problem since it is the underlying disease vindicating the euthanasia, which is of importance for quality control and statistics. There have been multiple publications emphasizing the need for autopsy to avert missing non-natural deaths, including homicides [3, 24]. For these cases, an extensive external examination combined with PMCTA and or minimal invasive autopsy would be recommended based on literature. Nevertheless, transportation, availability, and costs are limiting factors to put this into daily practice currently when there are no clinical suspicions. Furthermore, as for any subspecialty, assessment of post-mortem imaging requires a certain level of training, knowledge, and expertise, as was the case in our study [25-27]. This subspecialty is gaining each year with dedicated training programs, but is not yet present in all clinical centers. Lastly, there was a change in the CT scanner during the study period which might have improved diagnostic accuracy of the later cases. However, this possibly improved diagnostic accuracy is unlikely to be of significant influence on the study result.

In deaths without a known recent medical history attesting to the demise, PMCT could be used to identify or exclude a major underlying disease in addition to an autopsy or when an autopsy is not possible. Future studies should therefore focus on a broader population of out-of-hospital, suspected natural deaths with the additional use of autopsy and/or PMCT(A). With funding such a study, improvement of quality control and epidemiological statistics could be obtained and possibly a redistribution of funding in the future. Thus to conclude, our study suggests that there is added value for PMCT in the identification of diseases and illnesses leading to the demise in an out of hospital patient population.

Acknowledgements I. Dijkman and J.E. Lichtenberg have been of great contribution to the practical side of this study. Without the men and women who donated their bodies to science this research would not have been possible, we are therefore very grateful for their decisions to do so.

\section{Compliance with ethical standards}

Conflict of interest The authors declare that they have no conflict of interest.

Ethical approval This article does not contain any studies with animals performed by any of the authors. All procedures performed in studies involving human participants were in accordance with the ethical standards of the institutional and/or national research committee (granted exemption: METC-AMC 19-06-2017: W17 230 \# 17.269) and with the 1964 Helsinki Declaration and its later amendments or comparable ethical standards.

Informed consent Informed consent was obtained from all individual participants included in the study, prior to demise, for use of their body and medical information for scientific and educational purposes.

Open Access This article is licensed under a Creative Commons Attribution 4.0 International License, which permits use, sharing, adaptation, distribution and reproduction in any medium or format, as long as you give appropriate credit to the original author(s) and the source, provide a link to the Creative Commons licence, and indicate if changes were made. The images or other third party material in this article are included in the article's Creative Commons licence, unless indicated otherwise in a credit line to the material. If material is not included in the article's Creative Commons licence and your intended use is not permitted by statutory regulation or exceeds the permitted use, you will need to obtain permission directly from the copyright holder. To view a copy of this licence, visit http://creativecommons.org/licenses/by/4.0/. 


\section{References}

1. Goldman L, Sayson R, Robbins S, Cohn LH, Bettmann M, Weisberg M (1983) The value of the autopsy in three medical eras. N Engl J Med 308(17):1000-1005. https://doi.org/10.1056/ nejm198304283081704

2. Kircher T, Nelson J, Burdo H (1985) The autopsy as a measure of accuracy of the death certificate. N Engl J Med 313(20):12631269. https://doi.org/10.1056/nejm198511143132005

3. Kuijpers CC, Fronczek J, van de Goot FR, Niessen HW, van Diest PJ, Jiwa M (2014) The value of autopsies in the era of high-tech medicine: discrepant findings persist. J Clin Pathol 67(6):512-519. https://doi.org/10.1136/jclinpath-2013-202122

4. Shojania KG, Burton EC, McDonald KM, Goldman L (2003) Changes in rates of autopsy-detected diagnostic errors over time: a systematic review. Jama 289(21):2849-2856. https://doi.org/10. 1001/jama.289.21.2849

5. Koninkrijksrelaties BZe (1991) Wet op de lijkbezorging (Burrial Act). http://wetten.overheid.nl/jci1.3:c:BWBR0005009

6. Blokker BM, Weustink AC, Hunink MG, Oosterhuis JW (2016) Autopsy of adult patients deceased in an academic hospital: considerations of doctors and next-of-kin in the consent process. PLoS One 11(10):e0163811. https://doi.org/10.1371/journal.pone. 0163811

7. Burton JL, Underwood J (2007) Clinical, educational, and epidemiological value of autopsy. Lancet 369(9571):1471-1480. https:// doi.org/10.1016/s0140-6736(07)60376-6

8. Shojania KG, Burton EC (2008) The vanishing nonforensic autopsy. N Engl J Med 358(9):873-875. https://doi.org/10.1056/ NEJMp0707996

9. Turnbull A, Osborn M, Nicholas N (2015) Hospital autopsy: endangered or extinct? J Clin Pathol 68(8):601-604. https://doi.org/ 10.1136/jclinpath-2014-202700

10. Scholing M, Saltzherr TP, Fung Kon Jin PH, Ponsen KJ, Reitsma JB, Lameris JS, Goslings JC (2009) The value of postmortem computed tomography as an alternative for autopsy in trauma victims: a systematic review. Eur Radiol 19(10):2333-2341. https://doi.org/ 10.1007/s00330-009-1440-4

11. Battle RM, Pathak D, Humble CG, Key CR, Vanatta PR, Hill RB, Anderson RE (1987) Factors influencing discrepancies between premortem and postmortem diagnoses. Jama 258(3):339-344

12. Schwanda-Burger S, Moch H, Muntwyler J, Salomon F (2012) Diagnostic errors in the new millennium: a follow-up autopsy study. Mod Pathol 25(6):777-783. https://doi.org/10.1038/ modpathol.2011.199

13. Grabherr S, Heinemann A, Vogel H, Rutty G, Morgan B, Wozniak K, Dedouit F, Fischer F, Lochner S, Wittig H, Guglielmi G, Eplinius F, Michaud K, Palmiere C, Chevallier C, Mangin P, Grimm JM (2018) Postmortem CT angiography compared with autopsy: a forensic multicenter study. Radiology 288(1):270-276. https://doi. org/10.1148/radiol.2018170559

14. Rutty GN, Morgan B, Robinson C, Raj V, Pakkal M, Amoroso J, Visser T, Saunders S, Biggs M, Hollingbury F, McGregor A, West K, Richards C, Brown L, Harrison R, Hew R (2017) Diagnostic accuracy of post-mortem CT with targeted coronary angiography versus autopsy for coroner-requested post-mortem investigations: a prospective, masked, comparison study. Lancet 390(10090):145154. https://doi.org/10.1016/s0140-6736(17)30333-1

15. Eriksson A, Gustafsson T, Hoistad M, Hultcrantz M, Jacobson S, Mejare I, Persson A (2017) Diagnostic accuracy of postmortem imaging vs autopsy-a systematic review. Eur J Radiol 89:249 269. https://doi.org/10.1016/j.ejrad.2016.08.003

16. Blokker BM, Weustink AC, Hunink MGM, Oosterhuis JW (2017) Autopsy rates in the Netherlands: 35 years of decline. PLoS One 12(6):e0178200. https://doi.org/10.1371/journal.pone.0178200

17. Blokker BM, Weustink AC, Wagensveld IM, von der Thusen JH, Pezzato A, Dammers R, Bakker J, Renken NS, den Bakker MA, van Kemenade FJ, Krestin GP, Hunink MGM, Oosterhuis JW (2018) Conventional autopsy versus minimally invasive autopsy with postmortem MRI, CT, and CT-guided biopsy: comparison of diagnostic performance. Radiology 289(3):658-667. https://doi. org/10.1148/radiol.2018180924

18. van Rijn RR, Beek EJ, van de Putte EM, Teeuw AH, Nikkels PGJ, Duijst W, Nievelstein RA (2017) The value of postmortem computed tomography in paediatric natural cause of death: a Dutch observational study. Pediatr Radiol 47(11):1514-1522. https://doi. org/10.1007/s00247-017-3911-0

19. (RIVM) NIoPHatE (2017) Mortality rates: Netherlands cause of death statistics [Dutch: Sterftecijfers: CBS Doodsoorzakenstatistiek]. https://www.volksgezondheidenzorg. info/ranglijst/ranglijst-doodsoorzaken-op-basis-van-sterfte\#2823. Accessed 01-01-2019

20. Blokker BM, Wagensveld IM, Weustink AC, Oosterhuis JW, Hunink MG (2016) Non-invasive or minimally invasive autopsy compared to conventional autopsy of suspected natural deaths in adults: a systematic review. Eur Radiol 26(4):1159-1179. https:// doi.org/10.1007/s00330-015-3908-8

21. Latten BGH, Bakers FCH, Hofman PAM, Zur Hausen A, Kubat B (2019) The needle in the haystack: histology of post-mortem computed tomography guided biopsies versus autopsy derived tissue. Forensic Sci Int 302:109882. https://doi.org/10.1016/j.forsciint. 2019.109882

22. Caselli RJ (2003) Current issues in the diagnosis and management of dementia. Semin Neurol 23(3):231-240. https://doi.org/10.1055/ s-2003-814743

23. Knopman DS, DeKosky ST, Cummings JL, Chui H, Corey-Bloom J, Relkin N, Small GW, Miller B, Stevens JC (2001) Practice parameter: diagnosis of dementia (an evidence-based review). Report of the quality standards subcommittee of the American Academy of Neurology. Neurology 56(9):1143-1153

24. Campobasso CP, Laviola D, Grattagliano I, Strada L, Dell'Erba AS (2015) Undetected patricide: inaccuracy of cause of death determination without an autopsy. J Forensic Legal Med 34:67-72. https:// doi.org/10.1016/j.jflm.2015.05.008

25. Flach PM, Gascho D, Schweitzer W, Ruder TD, Berger N, Ross SG, Thali MJ, Ampanozi G (2014) Imaging in forensic radiology: an illustrated guide for postmortem computed tomography technique and protocols. Forensic Sci Med Pathol 10(4):583-606. https://doi.org/10.1007/s12024-014-9555-6

26. Flach PM, Thali MJ, Germerott T (2014) Times have changed! Forensic radiology-a new challenge for radiology and forensic pathology. AJR Am J Roentgenol 202(4):W325-W334. https://doi. org/10.2214/ajr.12.10283

27. O'Donnell C, Woodford N (2008) Post-mortem radiology-a new sub-speciality? Clin Radiol 63(11):1189-1194. https://doi.org/10. 1016/j.crad.2008.05.008

Publisher's note Springer Nature remains neutral with regard to jurisdictional claims in published maps and institutional affiliations. 